\title{
RAFAEL VÁZQUEZ ZAMORA, AGENTE CULTURAL EN LA ESPAÑA DE LA POSGUERRA
}

\author{
Blanca Ripoll Sintes \\ Universitat de Barcelona \\ blancaripoll@ub.edu
}

\begin{abstract}
RESUMEN: Este artículo pretende recuperar la figura de Rafael Vázquez, Zamora como agente cultural, fundamental para comprender la vida literaria de la España de la posguerra. Licenciado en Derecho, trabajó muy pronto como traductor gracias a su dominio de cuatro idiomas (inglés, francés, italiano y alemán) para editoriales como Apolo o Espasa-Calpe. Después de la Guerra Civil se convirtió en el representante del grupo Destino en Madrid: publicó numerosos artículos de crítica literaria en la revista homónima, tradujo numerosas novelas para su editorial y fue el sempiterno secretario del jurado del Premio Nadal de novela. Asimismo colaboró en la revista España de Tánger y en la sección teatral de Ínsula. Nuestro trabajo es un primer acercamiento a su figura desde el punto de vista de la historia cultural.

PALABRAS CLAVE: Rafael Vázquez, Zamora, crítica literaria, traducción, edición, Novela Española.
\end{abstract}

\section{RAFAEL VÁZQUEZ ZAMORA, CULTURAL AGENT IN POSTWAR SPAIN}

ABSTRACT: This article's aim is to recover the figure of Rafael Vázquez Zamora as a cultural agent, essential for understanding the literary life in postwar Spain. Graduated in Laws, he worked soon as a translator thanks to his language skills (in english, french, italian and german) for publishing houses as Apolo or Espasa-Calpe. After the Spanish Civil War, he became Destino's representative in Madrid: he published numerous articles of literary critic in the homonym magazine, translated several novels for its publishing house and was the everlasting secretary of the literary jury of the Nadal Prize of novel. Furthermore he collaborated in the magazine España of Tanger and in the theatre section of Ínsula. Our work is a first approach to his figure from the perspective of Cultural History.

KEYWORDS: Rafael Vázquez, Zamora, literary critic, translation, publishing houses, spanish novel.

Recibido: 07/04/2015. Aceptado: 23/07/2015 
Michel Espagne definía el concepto de "transferencia cultural" como la noción metodológica que establece las intersecciones, los diálogos y las tensiones entre espacios culturales o espacios nacionales (Espagne 2009: 201). En estos procesos relacionales de intercambio de ideas, motivos y símbolos culturales, es fundamental la actividad de dos factores añadidos: las políticas y los agentes culturales. Si atendemos a las circunstancias históricas que vivió nuestro país después de la Guerra Civil Española, será lógico concluir que las políticas culturales dictadas por el Estado se circunscribieron a las directrices ideológicas y morales propias de la compleja configuración política y religiosa del Franquismo.

No obstante, coexistieron algunas iniciativas dentro del sector de la cultura que, optando por la vía del posibilismo político, contribuyeron a generar una mayor diversidad de la que, a simple vista, los estrechos cauces del Régimen podían permitir. Entre estos proyectos, destacaría pronto, por su fecundidad y heterogeneidad temática, la figura de Rafael Vázquez Zamora, un auténtico agente cultural en la España de la posguerra que merece ser reivindicado y resituado en la historia literaria de este país.

Rafael Vázquez nace en Huelva, el 17 de diciembre de 1911, en el seno de una familia trabajadora': su padre, capataz del puerto de Huelva, muere prematuramente en torno a 1924-1925, dejando al cuidado de la madre, Concha Zamora, a un adolescente de 13 años. La interesante biografía de la figura materna explicará la posterior trayectoria profesional del joven Rafael: profesora de cinco idiomas (inglés, francés, portugués, italiano y alemán, que al parecer aprendió de forma autodidacta, comparando diccionarios) en la Escuela de Idiomas de Huelva, sacó adelante a su hijo a costa de muchas horas de trabajo en la academia. Rafael aprendió correctamente cuatro de las cinco lenguas que transmitía su madre: inglés, francés, italiano y alemán, y se especializó sobre todo en inglés (que practicaba con los marineros que recalaban en el puerto onubense) y francés, idiomas con los que se ganaría el sustento como traductor.

De sus años andaluces poco más se sabe, si bien hallamos su nombre entre los asistentes a la tertulia que algunas tardes se reunía en casa de José Cádiz Salvatierra, abogado y activo miembro de la vida cultural más cosmopolita de Huelva. El grupo de jóvenes "partidarios de todo lo nuevo", capitaneado por José Cádiz y

1. Agradezco la generosidad y amabilidad de los descendientes de don Rafael: de su hijo, Joaquín Vázquez Castro, y su nieta, Delfina Vázquez Balonga. A ellos debo mucha de la información biográfica, inencontrable en las pocas fuentes que estudian la vida y la obra del crítico y traductor andaluz. 
por el catedrático de latín José Marchena Colombo, director de la revista La Rábida, estaba integrado por Antonio Malo Zarco, catedrático de literatura en el Instituto de Bachillerato; Antonio Martín Mayor, poeta y escritor; Manolo de la Corte, pintor y escritor; Manuel Moreno Díaz, pintor; nuestro Rafael Vázquez Zamora; Carlos Rey, musicólogo; y los más jóvenes: Felipe Morales, Rafael Manzano y José Caballero (Madrigal Neira 2004: 36, n. 26). Sus reuniones se destinaban a recitar poesías, y a tratar cuestiones literarias y artísticas.

Si tenemos en cuenta que hacia 1928-1929 Vázquez Zamora se desplazaría a Madrid para cursar los estudios de Derecho, no es de extrañar que la tertulia cultural con el grupo de intelectuales y creadores de La Rábida marcara un punto de inflexión notable en los aprendizajes literarios de Rafael: la conexión con la modernidad y la vanguardia artística, el cosmopolitismo o la curiosidad por conocer todo lo nuevo, serían valores que acompañarían al crítico onubense durante toda su vida. Tampoco sería improbable que el joven políglota hubiera hecho sus primeras armas periodísticas y críticas en las páginas de La Rábida. Revista Colombina Iberoamericana (1911-1931), órgano de la Sociedad Colombina Onubense, puesto que numerosos artículos y crónicas aparecen sin firmar o con sintagmas vacíos como "La Redacción" o "El Cronista", si bien la crítica no ha apuntado esta posibilidad en los estudios más recientes (Cagiao Vila 2014: 9-14; Verdugo Álvez 2014: 15-53).

Ya en la capital española y después de licenciarse en Derecho por la Universidad de Madrid, Rafael Vázquez Zamora empezará a trabajar como traductor en editoriales como Espasa-Calpe o la barcelonesa Apolo, cuyo director literario era ya, a comienzos de la II República, el escritor y traductor Mario Verdaguer (Sanz Roig 2013: 194-195). Las obras de que se tienen constancia son la Vida de Jesucristo de Charles Dickens, publicada por Apolo en 1934 y con un interesante prólogo de Vázquez Zamora; y Los conquistadores españoles de Frederick Alexander Kirkpatrick $\left(1935^{2}\right)$ y El Imperio romano: el gobierno del mundo, la defensa del mundo, la explotación del mundo, de León Homo (1936), ambas en Espasa-Calpe. Es probable que el advenimiento de la Guerra Civil truncara la publicación, también en Espasa-Calpe, de Un "Banquete" moderno de G. Lowes Dickinson, traducción que tendría que esperar al traslado de la editorial madrileña a Buenos Aires para ver la luz en 1947, como volumen número 685 de la colección Austral.

En el citado Prólogo a la Vida de Jesucristo de Dickens, hallamos diversas ideas que serán fundamentales en la configuración del diapasón crítico que enar-

2. Traducción reeditada por Espasa-Calpe en su exilio bonaerense en 1942. 
bolará durante su quehacer como crítico literario en la España de la posguerra: el rechazo de una erudición que ahogue la vida palpitante del texto; la necesaria originalidad, personalidad, de la voz del autor; o un modelo crítico que anime a la lectura, que transmita la pasión por leer (en la línea azoriniana, como explicaremos más adelante) y que no quiere anticipar interpretaciones textuales que condicionen al lector -"Por estas mismas razones me he abstenido de hacer un análisis detenido del libro en este prólogo" (Vázquez Zamora 1934: 30).

En una plástica e irónica imagen, el traductor onubense transmite una visión sarcástica del trabajo de los eruditos, capaz de petrificar una obra de arte viva:

Si las mareas del tiempo y del Arte depositan un libro admirable, de aparición inesperada, en la playa de la Atención, hay unos individuos -primeros en descubrir la perla-, los eruditos, los sabios, que llevan siempre dispuesto el botiquín de urgencia de las notas al pie, los prólogos, epílogos, las adiciones y la estupenda colección de ascendientes posibles, seguros e imposibles, y descendientes hasta nuestros días. Todo ello surge rápidamente, junto al libro aun húmedo. Y las gentes vienen a verlo, las pobres gentes de corazón sencillo y modesto ambiente cultural. Acercándose, acercándose, helos aquí que se espantan porque la jaula donde han metido la perla es tan desproporcionada que solo se perciben los barrotes y los que están instalándolos. El precioso hallazgo, apenas si algunos alcanzan a verlo en todo su esplendor. Luego, los eruditos hablan de las fuentes y preguntan: ¿Cómo se formó el libro? ¿Procedencia de sus partes? ¿Influjo dominante de X. o de Z. En el todo? (Vázquez Zamora 1934: 11-12).

Resuenan las palabras de Unamuno en su primer ensayo de En torno al casticismo, cuando contrapone una "tradición eterna" (la vida intrahistórica, el fondo del mar) a una "tradición mentira que se suele ir a buscar al pasado enterrado en libros y papeles y monumentos y piedras" (Unamuno 2007: 80). Más que denostar el trabajo científico de los eruditos, Vázquez Zamora denuncia el distanciamiento que estos provocan entre la obra literaria y un público amplio. Las fuentes, considera Vázquez Zamora, no deben ser un fin sino un medio para que el autor, como un afluente "que corre hacia atrás" tome lo mejor de la tradición pasada y con ello nutra su particular expresión (Vázquez Zamora 1934: 13). Después de apuntar la preponderancia del género biográfico en su época, el escritor andaluz justifica dicho éxito en la reivindicación carlyleana de las figuras de "héroes" históricos, cuya impronta e influencia marcarían hitos decisivos en el devenir de la humanidad (Vázquez Zamora 1934: 19-21); reivindicación de la lectura de Carlyle que tiene mucho de la interpretación histórica de la religión cristiana de Miguel de Unamuno. 
La falta de documentación dificulta la reconstrucción de las redes culturales que el joven y brillante Vázquez Zamora pudo tejer en el Madrid anterior a la contienda. Sin embargo, no debemos menospreciar las posibles relaciones establecidas en Espasa-Calpe, en cuya colección "Vidas extraordinarias", dirigida por Antonio Marichalar ${ }^{3}$, apareció su traducción de Kirkpatrick. Con todo, se nos escapa una multitud de datos, que podría explicar que en 1932 y a la temprana edad de 21 años, firmara junto con Manuel Hidalgo el ensayo sobre psiquiatría criminal $L o$ inconsciente y el crimen, publicado por José M. Yagües en Madrid. Manuel Hidalgo, nacido el mismo año que Vázquez Zamora, había estudiado Psiquiatría, como asignatura de Magisterio Nacional, con el prestigioso psiquiatra y psicopedagogo César Juarros - de actitud progresista, era un temprano seguidor de las doctrinas de Freud y especialista en psiquiatría forense-, quien les firmó un elogioso prólogo para la publicación de su ensayo.

Punto axial de su formación crítica y literaria será la aventura de Eco. Revista de España, publicación trimestral de dificultosa localización que salió a la luz entre 1933 y 1935. Si bien la mayoría de estudiosos que mencionan la revista consideran a Vázquez Zamora como su director (Cano Ballesta 1972: 147; Molina 1990: 176; Rodríguez Espinosa 2004: 222), en las portadas de Eco éste aparece como "director literario" y Manuel Benet, como director artístico. Entre sus colaboradores, se hallaban su amigo Manuel Hidalgo; escritores y periodistas como Esteban Salazar Chapela, Eduardo de Ontañón, José Luis Sánchez Trincado o Antonio de Obregón; personalidades del ámbito diplomático como el cónsul general de Perú, Alberto Ureta, o Alfonso Hernández Catá, que desde 1933 era embajador de Cuba en Madrid, con los que bien pudo poner en práctica interés por Hispanoamérica aprendido en La Rábida; y destacados escritores de la época como Benjamín Jarnés, Alejandro Casona, Carmen Conde, Ramón Ledesma Miranda o el alicantino Julio Bernácer.

Si bien muchos de estos nombres propios habían crecido a la luz de la órbita de Ortega y Gasset, en medios como El Sol o Revista de Occidente, o editoriales como Espasa-Calpe (Ontañón publicaría en 1933 su biografía El Cura Merino, su vida en folletín), la revista dirigida por Vázquez Zamora pasaría a la historia literaria

3. Sobre el auge del género biográfico y colecciones editoriales auspiciadas por Ortega y Gasset como "Vidas Españolas e Hispanoamericanas", debemos señalar que está en curso la tesis doctoral, financiada por el Programa de Formación del Profesorado Universitario del Ministerio de Educación, Cultura y Deporte, de Jéssica Cáliz Montes, titulada El desarrollo de la "nueva biografía" en la colección 'Vidas Españolas e Hispanoamericanas del Siglo XIX', de Espasa-Calpe, bajo la dirección de la Dra. Marisa Sotelo Vázquez en la Universitat de Barcelona. Véase asimismo el estudio de Pulido Hidalgo (2009: 115). 
por publicar en 1934 -y acorde con los cambios estéticos de la época- el artículo de los hermanos Pedro y Carlos Caba titulado "La rehumanización del arte" (1934: 1-5) ${ }^{4}$. En él, se demandaba un alejamiento de la estética de vanguardia y "un reencuentro del arte y la literatura con el hombre sin ninguna clase de servilismos políticos" (Rodríguez Espinosa 2004: 222), quizá más cercano a los postulados teorizados por José Díaz Fernández en El Nuevo Romanticismo (1930). De algún modo, la revista Eco se erigiría en portavoz de esta nueva demanda estética -que hallaría un eco completamente ideologizado durante los años cuarenta en la España franquista-. Cano Ballesta cita, a propósito de la cuestión de la "rehumanización" en el género lírico, las irónicas palabras de su director, Rafael Vázquez Zamora:

¡Infeliz, ya veo que tu vida ha sido una nebulosa! Te consideraste satisfecho llevando tus poesías -llamaré así a lo que has hecho, por no irritarte- a la vida y no se te ocurrió dejar a la vida que entrara en tus versos, ni llevaste Poesía a la vida. Los confeccionadores de poemas en frío, hijo mío, son aquí poco estimados. La literatura, inexperto amigo, es cosa que se forja en la fragua, al calor de las pasiones, las sensaciones y las emociones. Vosotros, los falsificadores de lo poético -que es lo celestial-, los simuladores, no merecéis siquiera conocer el Infierno. Dante se opone a ello resueltamente. Nuestro Comité asesorador, de grandes poetas, ha hecho construir en el Limbo un amplio lugar lleno de humo y flores artificiales para los seres

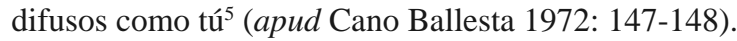

De similar apuesta estética sería la revista Rumbos (1935-1936) -no casualmente subtitulada Revista mensual de las artes y de la vida-, en la que también publicaría Rafael Vázquez algún texto (cotejando el vaciado de Pablo Rojas, podemos apuntar la posibilidad de que fueran artículos ya publicados en Eco, pues comparten título: "Jirones" - Rojas 2008: 15-16).

Paralelamente, podría haber trabado amistad con colaboradores de El Heraldo de Madrid, en el que también publicó reseñas y críticas literarias a partir del 28 de marzo de $1935^{6}$, como Luis Cernuda, José Bergamín, Julio Gómez de la Serna, Dámaso Alonso, César M. Arconada, Samuel Ros, César González Ruano o Guillermo Díaz-Plaja (Rodríguez Espinosa 2004: 222-223). Sin poder cerciorarnos

4. El lector interesado hallará referencias al artículo en Cano Ballesta 1972: 145-147; y Chicharro Chamorro 2004: 136. Y aparece transcrito en Ruiz Soriano 1997: 19-20.

5. La referencia original es: Rafael Vázquez Zamora, "Jirones", Eco. Revista de España, nº 9, octubre de 1934.

6. Con dos reseñas en la sección "Cubilete de dados", de Estampas de aldea de Pablo A. de Cobos, y de Historia de san Michele de Axel Munthe (Vázquez Zamora 1935: 4). 
por completo, es muy plausible que fueran González Ruano o Díaz-Plaja quienes pusieron en contacto a un Vázquez Zamora sin muchas plataformas de expresión a su alcance en los primeros años de la posguerra, con el grupo barcelonés de la revista Destino y la editorial homónima.

No obstante, es de gran interés la trayectoria profesional que, al calor de las circunstancias, emprende nuestro joven crítico y escritor durante la Guerra Civil española. Bajo el mando de la periodista Rosario del Olmo (colaboradora de $L a$ Libertad, Octubre o El Mono Azul, que realizó la famosa entrevista a Antonio Machado en el madrileño Café de Las Salesas), Rafael Vázquez trabajó para la II República en el Ministerio de Asuntos Exteriores, concretamente en el Departamento de Lenguas Extranjeras. Este hecho supuso que, en 1939, le sancionaran con un Expediente de Responsabilidades Políticas, al que apeló justificando que no se había sindicado antes de la contienda y que, como hijo de viuda, se había visto obligado a trabajar para mantener a su madre. Esta última cuestión seguramente le serviría de escudo para escapar de la sospecha de republicanismo que le habría impedido seguir traduciendo y escribiendo (al menos con su nombre real) en los periódicos, revistas y editoriales de la España franquista.

Bien por antiguas conexiones con la barcelonesa casa editorial Apolo, bien por su relación con firmas cercanas al grupo de Destino (César González Ruano, Guillermo Díaz-Plaja), el nombre propio de Rafael Vázquez Zamora aparecerá en las páginas del semanario barcelonés a principios de la década de los cuarenta. No es ésta ocasión de consignar la intrahistoria de la revista Destino, ni de cómo evolucionó desde sus orígenes como Boletín de F.E.T. y de las J.O.N.S. en el Burgos "nacional" hasta la publicación de talante liberal y destinatario burgués que fue hasta que su gerente, Josep Vergés, la vendió al político Jordi Pujol (Geli y Huertas Clavería 1991). Tampoco tenemos espacio suficiente para glosar cómo el mismo Vergés y Joan Teixidor crearon un sello editorial del mismo nombre, cuyas prensas alumbrarían novelas hoy ya canónicas, como Nada de Carmen Laforet, La sombra del ciprés es alargada de Miguel Delibes, El Jarama de Rafael Sánchez Ferlosio o Entre visillos de Carmen Martín Gaite. Ni de cómo el Premio Eugenio Nadal de novela se erigiría en tercer pilar de un proyecto periodístico-empresarial que perduró y mantuvo su hegemonía durante tres décadas. Sin embargo, de estas tres columnas debemos hablar, pues en todas participó, y de forma protagonista, Rafael Vázquez Zamora.

Atendamos ahora a su faceta como crítico literario. Su presencia no tuvo una continuidad semanal en Destino hasta 1946, fecha en que heredó la columna de Juan Ramón Masoliver, "La vida de los libros", que publicaría puntualmente en 
cada número hasta su fallecimiento en 1972. Desde dicho espacio, dispensó su mirada crítica hacia muy variados autores y géneros de la literatura española y de muy diversas literaturas extranjeras. Su amenidad y voluntad pedagógica harán que Dámaso Santos, años después, considere a Vázquez Zamora como el crítico que dio la lección más "clarificadora" de crítica literaria en la España de la posguerra, misión a la que aportó "su sensatez, rigor, transparencia y buenos modos en los periódicos y revistas para dar cuenta cabal y honesta interpretación de una clase de hechos, acontecimientos que el periodista tan difícilmente valora" (Santos 1987: 148).

Contrapunto cultural de Destino con sus noticias desde la capital del Estado, Vázquez Zamora fue un brillante escaparate, un gran publicista de las novedades literarias madrileñas, de forma que se compensaba la omnipresencia, por cercanía geográfica y por interés del grupo Destino, de las novedades editoriales barcelonesas. Así pues, la doble atención a la literatura española y a la europea y norteamericana lo convirtió en un gran puntal de información. Rafael Vázquez vivía la literatura en primera persona y conocía directamente a muchos de los escritores que reseñaba en sus críticas (probablemente a través de su asistencia a tertulias literarias tan reconocidas como la del Café Gijón durante la posguerra), que a su vez entrevistaba para el semanario barcelonés. Por otro lado, la crítica destacaría asimismo su igual respeto tanto por las figuras más relevantes como por los escritores noveles: "Su proximidad personal a los nuevos narradores, su complicidad con ellos y la frecuentación de las mismas tertulias y locales, o el hecho de ser jurado de numerosos premios, empezando por el Nadal, hicieron de él una mina de información interesante sobre los nuevos escritores" (Gràcia y Ruiz Carnicer 2001: 249). La nostalgia de su patria chica, Andalucía, lo erigió en el mejor defensor de la literatura de su tierra de origen. Así lo aseveraba Antonio Burgos:

El crítico onubense, afincado en Madrid, fue el que inventó el "tremendismo literario" cuando Cela publicó La familia de Pascual Duarte y fue el primero que habló de la "nueva narrativa andaluza", deslumbrado por los cuentos de Alfonso Grosso que había leído como jurado del premio Sésamo, por las novelas de Manuel Barrios que había votado como jurado en el Nadal, El crimen o La espuela. No había hecho literario en la Andalucía de los 50 y los 60 que Vázquez Zamora no consignara puntualmente en su página del España Semanal. Reseña hizo de todas las revistas poéticas y los libros de versos de los autores de Granada (Veleta al Sur), de Sevilla (Guadalquivir, Rocío, Aljibe), de Córdoba (Arcángel), de Cádiz (Platero, Caleta), de Arcos (Alcaraván, Liza) (Burgos 1997).

A la hora de dictaminar cuáles fueron sus modelos críticos, debemos precisar que el modo de proceder de Vázquez Zamora fue más divulgativo que erudito, si- 
guiendo con una premisa pedagógica que ya observamos en su quehacer anterior a la Guerra Civil. La amenidad con que revistió sus textos críticos tuvo también eco en la heterogeneidad temática y genérica de los volúmenes que analizaría en sus artículos: ensayo, novela, teatro o poesía.

Para elucidar qué diapasón crítico enarbolaría don Rafael en las páginas de Destino vamos a detenernos en algunos ejemplos de novela española coetánea ${ }^{7}$. Vázquez-Zamora, por encima de las modas, de las capillas y de los falsos profetas literarios, y gran lector de Oscar Wilde, hacía suya la famosa frase que escritor británico antepuso en el "Preface" a The Picture of Dorian Grey: "There is no such thing as a moral or an immoral book. Books are well written, or badly written. That is all" (Wilde 1985: 3), y la transformaba en el siguiente lema: "Después de todo, existe una clasificación eficaz y eterna: novelas malas y novelas buenas" (Vázquez Zamora 1944c: 13). En efecto, el crítico andaluz intentará facilitar a sus lectores sus impresiones de lectura y sus juicios, ejercerá a modo de filtro, de test de calidad para distinguir lo bueno de lo malo.

Fue él, como apuntaba Burgos, quien acuñó el término "tremendismo literario", si bien se señalan a otros autores como padres del concepto: Martínez Cachero considera al poeta Antonio Zubiaurre como su inventor (1997: 114-115). La noción teórica, luego tan aplicada por la crítica posterior, y sobre todo por el mismo Vázquez Zamora, sería utilizada para referirse a la corriente supuestamente inaugurada por Camilo José Cela y su novela La familia de Pascual Duarte. Una corriente que se caracterizaba, a juzgar del crítico, por una estética realista -que recogía asimismo los aspectos más sórdidos de dicha realidad- y por una ética de cariz existencialista en la línea de La náusea de Sartre ${ }^{8}$, que retrataba el conflicto individual de la persona en lucha con una sociedad también en conflicto. Vázquez Zamora, quizá de forma inconsciente, esbozaría entonces el concepto narratológico del siguiente modo: "Hay en estas páginas escenas de una tremenda intensidad realista, pero nos las presenta el autor a través de un invisible barniz artístico que las hace perfectamente novelables" (Vázquez Zamora 1943: 10).

Vázquez Zamora elogiará este tipo de realismo de Cela: aquel que, sin omitir detalles desagradables, logra un "relato sobrio, teñido de una amargura agradable"

7. Ejemplos extraídos del vaciado presente en nuestra tesis doctoral La crítica de la literatura española en el semanario "Destino" (1939-1968). La novela, dirigida por el dr. Adolfo Sotelo Vázquez y defendida el 2 de junio de 2011 en la Universitat de Barcelona. Véase Ripoll Sintes 2012.

8. Josep Pla (con el pseudónimo “Tristán”), en “Jean-Paul Sastre y el 'tremendismo' literario”, va a vincular directamente a Sartre con la obra celiana (Pla 1947: 6-7). 
(Vázquez Zamora 1943: 10). En cambio, aborrecerá a todos aquellos imitadores que, aprovechando el magnífico filón celiano -y aprovechándolo mal-, se excedieron en aquello del "tremendismo" y se dedicaron banalmente a acumular tragedias, groserías y sordideces, sin intención artística alguna. En otro artículo, titulado “¿Conoce usted la vida?”, hará referencia a este tipo de exageración estética: "Así, lo lamentable del 'tremendismo' en literatura (permítaseme este neologismo tan gráfico que ofrezco a nuestros tratadistas), lo censurable en él no es su tendencia a lo sombrío, sino el que sus sombras no sean producidas por una luz" (Vázquez Zamora 1945a: 13). Cabe resaltar la clara conciencia que Vázquez Zamora tiene de estar creando a la vez método para la historia y la crítica literarias (etiqueta a los autores, suele marcar etapas en su producción, etc.) y su voluntad de mostrar la paternidad del concepto de tremendismo: "permítaseme este neologismo tan gráfico que ofrezco a nuestros tratadistas" (Vázquez Zamora 1945a: 13).

Con el tiempo, va a cambiar su consideración de la opera prima de Camilo José Cela. Incluso el tremendismo del Pascual Duarte -como explica en "Alrededor de una colmena" (Vázquez Zamora 1946: 13) - contiene unos dogmas demasiado inamovibles: los personajes están demasiado sujetos a su trágico destino, no se da cabida a la voluntad humana ni a su libre albedrío. La crítica principal que, a la altura de 1946, dirige Vázquez Zamora al tremendismo radica en su escasa conexión con la vida, con lo real, de manera que el crítico onubense está siguiendo los mismos dictados estéticos que sus contemporáneos: la literatura debe beber de la vida y devolverla, transformada, al lector. En este sentido, debemos recordar cómo Rafael Vázquez ya había enarbolado hacia 1934 las banderas estéticas de la rehumanización literaria en su revista Eco y cómo esta misma propuesta se había generalizado durante la primera década de la posguerra española, aunque, si bien no en el caso de Vázquez Zamora, se había ideologizado y delimitado políticamente.

Con la crítica a la novela En la otra orilla de Juan Manuel Pombo Angulo da comienzo a su prolífica y longeva etapa en Destino bajo el marbete "La vida de los libros", columna donde desarrollaría un método crítico que, sin caer en excesivos lirismos retóricos, recuerda inequívocamente a la crítica literaria "impresionista" (Sobejano 1962: 74-90) desarrollada y defendida a principios de siglo XX por José Martínez Ruiz "Azorín”. Nos hallamos, entonces, ante críticas que pretenden sugerir al lector, envolverle en un halo literario y animarlo a la lectura de la obra en sí; que quieren elogiar una obra o un autor determinado y transmitir esa pasión al público.

Es evidente el antecedente azoriniano de este modelo de crítica literaria -y, tras la pluma de Martínez Ruiz, también son obvios los paradigmas anteriores de 
los críticos franceses Paul Bourget, Jules Lemaître o Anatole France-. En este sentido, Azorín defendía que la labor del crítico no es sólo la del analista, sino que debe tener cierta capacidad de creación literaria, ciertas dotes de artista. Asegurará en su breve prólogo "La crítica" -a la quinta parte de las Páginas escogidas-: "Toda crítica, aún la más unipersonal, aún la más objetiva, es una impresión" (Martínez Ruiz 1917: 217). Que Vázquez Zamora se adscriba a este modelo, sin duda alguna, lo vincula a un quehacer crítico de clara resonancia institucionista, en lo que se refiere a la educación de la sensibilidad y del gusto del público.

Hecho habitual durante el primer lustro de los años cuarenta, el crítico andaluz defenderá como paradigmas novelescos a los dos maestros vivos, Azorín y Baroja, como bien lo demuestran en su defensa de las Memorias barojianas (1944b: 7) o su "Carta sin sobre a María Fontán" (1945b: 21-22), artículo extenso dedicado a la novela María Fontán de Martínez Ruiz. El irónico artículo de Vázquez "El despiadado don Pío" debe inscribirse en una breve polémica abierta en Destino por un feroz artículo de Guillermo Díaz-Plaja ante la próxima publicación del texto autobiográfico del novelista vasco, un éxito editorial al que probablemente contribuyeron los múltiples debates que sugirió su publicación. La cita de Díaz-Plaja (bajo la máscara de "Sagitario") es sólo un breve párrafo de la columna "La saeta en el aire" que mostramos completo para que no se pierdan matices:

Sobre las Memorias de Baroja. -No acierto a comprender qué se propone Pío Baroja con la publicación -en forma de gran espectáculo- de sus Memorias. Nada más lamentable, porque nada podía defraudar más a la etopeya que Baroja había fraguado de sí mismo. Cerca de medio siglo, en efecto, nos ha estado diciendo de su menosprecio a las vanidades de la vida literaria, de su espléndido aislamiento insobornable, de su arisca independencia. Y he aquí que ahora demuestra que hace más de cuarenta años viene acumulando rencor contra tal crítico, contra tal escritor, contra tal colega, porque le negaron algo en la vida social o en la vida literaria...

El primer libro de Baroja se titulaba Juventud y egolatría. Toda su obra es una continuación de este título primero (Díaz-Plaja 1943: 10).

Rafael Vázquez Zamora respondió con "El despiadado don Pío", artículo en que arguye que la publicación de las Memorias no desvaloriza su figura como novelista y que, en la sempiterna defensa barojiana de la libertad creativa, debemos situar también su libertad a la hora de expresar o no sus recuerdos e impresiones:

Baroja es duro, sí, pero con la dureza que puede prevenirse. Además, si dice-sobre este o sobre aquel- cosas que pueden parecer desagradables, no las dice porque no le han publicado un artículo. Así, este escritor debe su fama de cruel y despiadado a su lamentable error de ser sincero. Naturalmente, tú y yo podemos no estar con- 
formes con los juicios tajantes de don Pío, pero el hecho de que a él le parezca tonto quien a nosotros nos parece un genio, sólo nos autoriza a decir "Me parece que don Pío se equivoca", pero nunca "Baroja es un esto o un lo otro". Pensemos que él se propuso escribir novelas y que ha escrito verdaderas novelas (Vázquez Zamora 1944b: 7).

Asimismo adalid de José Martínez Ruiz, a quien trataría con cierta asiduidad en el Madrid de la posguerra, como demuestran sus diversas entrevistas y artículos publicados en Destino 9 , elaborará una particular "Carta sin sobre a María Fontán": una reseña peculiar en la que, dirigiéndose a la protagonista del relato, elogia al autor. Como si el personaje de Azorín estuviera tan vivo en las páginas de la novela que Vázquez Zamora se dirigiera al mismo en una crítica en forma epistolar: una carta abierta que repasa su constitución como personaje (mujer imprevisible, culta, que inspira ternura) o la estructura de la obra: 31 capítulos que, como en la obra de los hermanos Goncourt, dan una visión muy real de la vida pero de un modo fragmentario, impresionista (Vázquez Zamora 1945b: 21-22).

Los aspectos del género narrativo que más captan la atención de Vázquez Zamora son fácilmente extraíbles de su labor crítica: la psicología real y "viva" de los personajes; un diálogo verídico, natural y adecuado a sus hablantes; la capacidad de observación de la realidad del novelista; la traducción del mundo interior del autor, vertido en el resultado literario; etc. Y halla un obstáculo capital para el renacer de la novela española del momento:

Me parece que la escasez de novelistas en España -y en proporción a la importancia de nuestro idioma y nuestra literatura, es lamentablemente reducido el número de novelistas que pueden figurar en la Lista Grande-, que esta escasez, digo, se debe al débil voltaje de la imaginación literaria española. Somos unos realistas irremediables (Vázquez Zamora 1948a: 14).

Para paliar este problema, Vázquez Zamora aboga no por que se pierdan los novelistas en mundos exóticos e irreales, sino por una búsqueda en lo humano, en el interior del hombre. Para ello, el autor debe bucear en sus entrañas para dibujar mundos reales, emocionalmente vívidos y, a la vez, universales en tanto que radicalmente humanos. Destacará precisamente este aspecto en el Premio Nadal 1947: "Y, sobre

9. En cuanto a Azorín, Rafael Vázquez-Zamora publicará en Destino además de su reseña a María Fontán, entrevistas y retratos del autor levantino: "Cinco minutos con Azorín" (Vázquez Zamora 1944a: 10); "Azorín, ermitaño en el bullicio" (Vázquez Zamora 1945b: 19); o "Un día cualquiera de Azorín" (Vázquez Zamora 1947: 10). 
todo, hay que loar en Miguel Delibes su sinceridad literaria; el no haber recurrido a procedimientos ajenos a su temperamento" (Vázquez Zamora 1948b: 16).

En esta defensa de un realismo humano y vigente se inserta la crítica a los excesos del tremendismo de Vázquez Zamora. Porque asegura, a propósito de Sobre las piedras grises de Sebastián Juan Arbó, “atrevimiento es hoy desarrollar un asunto de tan extremada sencillez y escribir un libro que se puede leer sin náuseas ni escalofríos" (Vázquez Zamora 1949: 15-16), dada la gran proliferación de falsos imitadores de la estética celiana.

A finales de 1950 y ante la evidencia de que algunos novelistas persisten en el error, a su juicio, de seguir cultivando el tremendismo estético, va a llegar a la siguiente conclusión:

Expreso con tanta insistencia mi oposición a la literatura "angustiosa", a las novelas, a los poemas y dramas cuyo asunto es, sistemáticamente, la angustia de vivir de nuestro tiempo, la desesperación y los encantos de la cloaca, que ha de insistir casi tanto en mi absoluto convencimiento de que nuestro tiempo es, efectivamente, angustioso y en que me parece evidente la autenticidad de la angustia comunicada literariamente por una minoría de escritores (Vázquez Zamora 1950: 15).

Tanta proliferación de literatura tremendista le va a parecer una muestra sincera, ya no exagerada, de un estado generacional, de una situación social comúnmente extendida. Ante esta circunstancia, considera inútil que se busquen influencias extranjeras en la producción literaria española, pues todo responde al ambiente nacional:

Es, por tanto, preferible creer que la atmósfera de la novela actual y su preocupación por ciertos temas es algo que se halla en la atmósfera de nuestro tiempo y que las condiciones duras de vida o la tendencia a desnudar el estilo de inútiles encajes es una tendencia universal determinada por factores extraliterarios comunes a diversos países (Vázquez Zamora 1951: 15-16).

No obstante, la defensa de la voz original y personal nos lleva asimismo a vincular la tarea crítica de Rafael Vázquez después de la Guerra Civil con la desempeñada antes de la contienda: el crítico andaluz consideraba fundamental supeditar el estudio de las fuentes ajenas, a la reivindicación del estilo propio de cada escritor. En el rechazo a elucidar las fuentes literarias de una obra no existe desprecio alguno de la labor de científicos y eruditos, sino la crítica de la petrificación de la obra literaria que se deriva de la tarea de los académicos. Vázquez Zamora quería mostrar textos vibrantes, palpitantes, a ojos de sus lectores y consideraba innecesario, quizá 
un esnobismo, rastrear genealogías de fuentes literarias precedentes. Este talante le llevó a un cordial y breve debate con otro de los críticos literarios de Destino, el profesor universitario Antonio Vilanova, que desarrolló, en efecto, en las páginas de la revista barcelonesa un modelo crítico mucho más erudito, sin menoscabar la reivindicación de la originalidad y de las emociones contenidas en los libros analizados ${ }^{10}$.

En su diapasón crítico, Antonio Vilanova se insertaba en la tradición iniciada por Américo Castro, José Ortega y Gasset o Federico de Onís, quienes defendían una forma de entender y de analizar la literatura en su historia, a partir de la conexión con las "circunstancias" que la vieron nacer y en perenne vínculo con la Europa de su tiempo. Vázquez Zamora reaccionaría frente a este modelo crítico en un artículo dedicado a la novela de Alejandro Núñez Alonso, La gota de mercurio, finalista del Premio Nadal 1953 y publicada por Ediciones Destino en 1954:

Se ha dicho hasta la saciedad que La gota de mercurio está escrita con estilo proustiano. Se ha citado también con este motivo a Joyce, Kafka, Mann, Huxley, Faulkner y demás grandes de la novela contemporánea. Pues bien, digo yo que si Núñez Alonso ha sido capaz de poner a su servicio todas las conquistas que en el arte de la expresión novelística debemos a aquéllos, hay que saludarlo como un verdadero novelista de nuestro tiempo. Pero si reflexionan ustedes, comprenderán en la imposibilidad de construir una novela tan personal (y hasta "personalista") como La gota de mercurio recurriendo exclusivamente a herramientas prestadas (Vázquez Zamora 1954: 32-33).

Hallaremos otros ejemplos de ironías en este sentido en su análisis crítico de Funcionario público, segunda novela de Dolores Medio: "Partiendo de esta aparente perogrullada, hay que reconocer que aquel libro necesita poseer además alguna otra cualidad para que -sin ser rosa, ni erótica, ni extranjerizante-interesase a grandes masas de público" (Vázquez Zamora 1957: 32). Y añade:

Comprendo que estos temas que prefiere Dolores Medio molesten y sean considerados vulgares. En tal sentido, Funcionario público reincide en el "pecado" de Nosotros los Rivero: no se parece en nada a las novelas de Hemingway, a las de François Mauriac, ni a las de Charles Morgan o Virginia Woolf, por citar, a voleo, nombres que son indiscutibles (Vázquez Zamora 1957: 32).

10. En Geli y Huertas Clavería (1991: 106-109), se habla de "El tiempo de los críticos literarios" para referirse a la época dorada de la revista, los años cincuenta. 
Fueron muchos los intercambios irónicos entre ambos críticos, siempre desde la amabilidad y el respeto mutuos (Ripoll Sintes 2011: 169-176). Cabe concluir, en este aspecto, que la actitud de Vázquez Zamora respondió siempre a la voluntad de divulgar, de difundir la lectura entre un público cuanto más amplio mejor.

Además de su semanal colaboración crítica en Destino, la pluma de Rafael Vázquez asomará en las páginas de la revista España de Tánger hasta su muerte en 1972 y llevará a cabo la crítica teatral de la revista Ínsula, con una puntualidad casi mensual, desde el mes de enero de 1952 hasta 1965 (fecha en que será sustituido por el joven José María de Quinto). Quedará para una futura ocasión un examen más detenido de la importante aportación a la revisión de la actualidad dramatúrgica realizada por Rafael Vázquez Zamora en la publicación fundada por Enrique Canito y José Luis Cano. En Ínsula el crítico onubense repasó los estrenos madrileños tanto de autores nacionales como extranjeros (Pirandello, Chéjov, Endhard, Anouilh, O'Neill, y también obras de García Lorca, y los coetáneos Sastre o Bueno Vallejo), nómina que muestra a las claras su gusto estético y su posicionamiento ético.

Definidos ya los parámetros de Rafael Vázquez como crítico literario, es imprescindible atender a otra de sus facetas como agente cultural: su participación en numerosos jurados de premios literarios. Desde la creación del premio hasta su fallecimiento (1944-1972) detentó el cargo de Secretario del Premio Nadal de novela, iniciativa fundada por Ignasi Agustí, Josep Vergés y Joan Teixidor, que se servía de la revista Destino como gran plataforma de difusión y cuyos ganadores y/o finalistas veían su novela publicada en las prensas de Ediciones Destino. El Premio Nadal se constituyó en un auténtico hito sociocultural, pues marcaba el inicio del calendario de eventos en la ciudad de Barcelona y se erigió en modelo de los grandes premios literarios que se crearon a posteriori (Ripoll Sintes e.p.). Rastreamos asimismo su presencia en el premio Simenon de novela policíaca, organizado por la editorial barcelonesa Aymá y en un concurso fundamental para la reivindicación literaria del género del relato breve, como fue el Premio Sésamo, que dio a conocer a importantes nombres propios de la novela española contemporánea (Juan Marsé, como botón de muestra).

Su participación en estos heterogéneos jurados literarios le permitió palpar de primera mano la naciente creación narrativa española: las diversas tentativas de los jóvenes, la variedad de estéticas y corrientes literarias que pugnaban por mostrarse en los escaparates de nuestro país en épocas complejas y difíciles como los años cuarenta y cincuenta. 
Por último, cabe destacar la labor como traductor durante la posguerra española de Rafael Vázquez Zamora. Básicamente circunscrita a Ediciones Destino, su tarea traductológica concedió a los lectores españoles el acercamiento a obras fundamentales de Virginia Woolf, T. Lobsang Rampa, George Orwell, Czeslaw Milosz, Saul Bellow, Richard Hughes, Joseph Conrad, Joyce Cary, William Thackeray, Vintila Horia, Sinclair Lewis o Walter Scott. La mayoría de estas traducciones aparecieron por primera vez entre 1950 y 1960 y muchas de ellas se mantienen vigentes en reediciones actuales ${ }^{11}$. También en esta ocasión, la revista Destino servía a modo de expositor y difusor de las novedades extranjeras traducidas en la editorial homónima. En este sentido, cuando se publicaba una de estas obras traducidas, el semanario ofrecía a sus lectores un fragmento (normalmente el principio del primer capítulo) de la novela, a modo de cuento ilustrado. Pese a que estamos frente a una evidente maniobra de publicidad empresarial, la presencia de traducciones de novelas extranjeras en los años cuarenta y cincuenta convirtió a la revista Destino en un oasis cultural en la España autárquica de la época. En esta sección de relatos ilustrados, que también brindaría su espacio a escritores nacionales como Miguel Delibes, Carmen Laforet, Ana María Matute o Camilo José Cela, Rafael Vázquez Zamora publicará traducciones de autores como Leonida Repaci, Arnold Bennett, Marcel Pagnol, Edgar Allan Poe, Robert L. Stevenson, Hugh Clifford, Richard Hughes, Willa Carter, Rudyard Kipling, Henry Troyat, Aldous Huxley o Stephen Leacock (Ripoll Sintes 2013).

11. Facilitamos a los lectores el catálogo completo de las traducciones de Vázquez Zamora en Destino: George Orwell, 1984 y La marca; John Moore, Las aguas subterráneas; Eric Williams, Águilas en tinieblas y El caballo de madera; E. R. Braithwaithe, Al Señor con cariño; William Thackeray, Las aventuras de Barry Lyndon; André Maurois, Bernardo Quesnay, Dickens y Meipe; Vintila Horia, El caballero de la resignación, Dios ha nacido en el exilio y Los imposibles; Pierre Boulle, La cara; Victoria Holt, La confesión de la reina, La mujer secreta y La señora de Mellyn; Laurens Van der Post, El corazón del cazador, Feliz Navidad Mr. Lawrence, El mundo perdido del Kalahari y Viaje por Rusia; Margaret Kennedy, Cuenta nueva y Los oráculos; Edward Ashcroft, De Gaulle; H. E. Bates, Delicia de mayo; Iris Murdoch, Una derrota bastante honrosa y La muchacha italiana; John Meade Falkner, El diamante; Joseph T. Shipley, Diccionario de la literatura mundial: crítica, formas, técnica; Maria Dermoût, Las diez mil cosas; Joseph Conrad, Entre la tierra y el mar y Freya, la de las Siete Islas; Joyce Cary, Un espantoso placer y Mister Johnson; Sinclair Lewis, Este inmenso mundo; Karl Bjarnhof, Las estrellas palidecen; Virginia Woolf, Flush; Lynne Reid Banks, La habitación en forma de I; Saul Bellow, Herzog, Las memorias de Mosby y otros relatos, y El planeta de Mr. Sammler; Duff Cooper, La hora de aquel corazón; Richard Hughes, Huracán en Jamaica; T. Lobsang Rampa, El médico de Lhasa, El tercer ojo: autobiografía de un lama tibetano, y La túnica azafrán; Ambroise Vollard, Memorias de un vendedor de cuadros; Walter Scott, La novia de Lammermoor; Czeslaw Milosz, El poder cambia de manos; Rebecca West, Rosas blancas a las cuatro; Robert Crichton, El secreto de Santa Victoria; Fletcher Knebel, Siete días de mayo; y Gilbert Cesbron, Soltad a Barrabás. 
La dimensión triangular de Rafael Vázquez Zamora como agente cultural en la España de la posguerra (traducción, crítica literaria, jurado de premios literarios) concedió heterogeneidad y amplitud de horizontes al legado cultural que forjó durante su trayectoria. Rafael Vázquez fue una pieza fundamental de la reivindicación estética de una rehumanización literaria en la España de la II República y continuó enarbolando dicho criterio en su tarea de recepción de la más reciente creación literaria tanto española como foránea. Asimismo, fue pilar indiscutible del proyecto del grupo Destino (revista, editorial y premio Nadal) como traductor, crítico y jurado de reconocida valía y rigor. Y pese a tener un diapasón estético coherentemente defendido durante varias décadas y pese a su insobornable honestidad crítica, Vázquez Zamora tuvo la generosidad y la curiosidad de espíritu suficientes para estar abierto a las novedades literarias, siendo ajeno a cualquier tipo de prejuicio.

Esta última cuestión se revela en el grato recuerdo que el crítico andaluz dejó en muchos escritores jóvenes que lo trataron. Así, en una entrevista del 2002, Juan Eduardo Zúñiga y Antonio Ferres le recordaban como adalid indiscutible del grupo de jóvenes novelistas reunidos en torno a la publicación Acento Cultural y que representaron el Realismo Social español de los años cincuenta:

Juan Eduardo Zúñiga: [...] El caso es que el grupo se fue cohesionando cuando Armando López Salinas, muy aficionado a la pintura, empezó a escribir cuentos. Él fue el núcleo de ese grupo de jóvenes con aspiraciones literarias que impulsó lo que luego se dio en llamar el socialrealismo. El grupo existió literariamente gracias al apoyo de Rafael Vázquez Zamora, secretario del Premio Nadal y representante de la editorial Destino en Madrid. Una persona excelente.

Antonio Ferres: Excelente, sí. En Destino fueron publicadas Central eléctrica, de Jesús López Pacheco, en 1958, y también mi primera novela, La piqueta. Y enseguida La mina, de Armando López Salinas, y luego La zanja, de Alfonso Grosso (Echevarría 2002).

Con algo más de sorna pero igualmente lleno de ternura, Juan Benet nos deja este retrato de Rafael Vázquez en Otoño en Madrid hacia 1950:

Muchos años más tarde conocí a Rafael Vázquez Zamora, un buen hombre alto y desgarbado [que al decir de Ferlosio tenía dos voces], con unas gafas como culos de botella, que trabajaba como asesor literario y lector de manuscritos para un editor catalán de cuyo nombre quisiera no acordarme (Benet 1987: 87).

Editor catalán que no era otro sino Josep Vergés, cuya fama de riguroso pero avariento quebró relaciones con más de un escritor. Bien es cierto que la mala relación entre el editor catalán y el novelista Benet podría proceder del rechazo inicial 
de Vergés hacia Volverás a Región, como recuerda Ana María Moix en una entrevista realizada por Íñigo García Ureta (2011: 59); rechazo solo salvado por la intermediación de Dionisio Ridruejo, quien consiguió que Ediciones Destino publicara la novela. Prosigue Juan Benet con la sabrosa anécdota con Rafael Vázquez, escena que da buena cuenta de su personalidad:

[...] una noche calurosa nos invitó a cenar a un restaurant de lujo; para empezar R. V. Z. pidió gazpacho y cuando le fue servido el caldo se acercó otro reverente camarero a ofrecerle la consabida bandeja múltiple de pan, cebolla, pepino, tomate y no sé qué más picado. A la oferta del camarero replicó con un distraído "sî́" que al no venir acompañado del complementario "basta" obligó al camarero a vaciar sobre su taza todo el contenido del sector pan. Con mucho R. V. Z. prefería hablar de literatura antes que atender a la composición de su gazpacho; con la cebolla ocurrió lo mismo que con el pan y el caldo desbordó la taza para inundar el plato; con el pepino la inundación llegó al mantel y con el tomate a la falda de mi mujer -sentada a su lado-que me lanzó una mirada de socorro para solicitar una intervención que remediara aquel desastre. Intervención que naturalmente yo no llevé a cabo. Cuando al fin se retiró el camarero, sin un grano en su múltiple bandeja, R. V. Z. se limitó a un somero "gracias" para encararse con lo que más que un gazpacho parecían "los estragos de los pasados temporales" tan frecuentes en la prensa de entonces (Benet 1987: 87).

La cena culmina con el acercamiento hasta el domicilio del crítico, acompañado por el novelista y su esposa, y la abierta despedida no puede sino ofrecernos un clarividente retrato de la inmersión total, vital, de Vázquez Zamora en el mundo literario:

Para rellenar el trayecto le pregunté si leía muchas novelas. “¿Novelas?” y me miró sorprendido. "Quiero decir manuscritos”, corregí un poco cortado. “¿Manuscritos? ¿Novelas? Oh, sí, cómo no, he leído algunos manuscritos y novelas; sobre todo novelas, muchas novelas; toda clase de novelas, de todo tipo; he leído centenares de novelas, qué digo centenares, miles; miles y miles de novelas; novelas y nada más que novelas; todo el día leyendo novelas, no he hecho otra cosa que leer novelas; millares de novelas, yo creo que he leído todas las novelas". Habíamos llegado al punto donde debía bajarse y yo tendí el brazo para abrir la portezuela; pero no se movía, la mirada clavada en un punto oculto por los gruesos cristales de las gafas, su pensamiento extraviado en las constelaciones del universo novelístico. Creo que murió poco después -estoy hablando de 1968- y su postrer imagen se quedó grabada en mi memoria: alejándose por las sombras de la Avenida de La Habana, mientras repetía "novelas, novelas, millares de novelas..." y por encima de la frente agitaba la mano como para despejar las interrogantes de una pesadilla (Benet 1987: 87-88). 
Crítico literario, traductor políglota conocedor de cuatro idiomas y miembro activo de la vida cultural española durante la difícil etapa histórica de la dictadura franquista, Rafael Vázquez Zamora moría el 21 de junio de 1972 dejando un legado imperecedero, pues se halla en letras de molde, pero injustamente olvidado por la academia y por la sociedad española actual. Quede este artículo como homenaje y reivindicación de su figura.

\section{Bibliografía}

BENET, J. (1987). Otoño en Madrid hacia 1950. Madrid: Alianza Editorial.

BURGOS, A. (1997). "El España de Tánger, periódico andaluz", El Mundo de Andalucía, sábado 11 de enero de 1997. <http://www.antonioburgos.com/memorias/ 1997/memotanger.html>. (Acceso 6 Mayo 2015).

CABA, P.; CABA, C. (1934). "La rehumanización del arte". Eco. Revista de España 9 (octubre): 1-5.

CAGIAO VILA, P. (2014). "Introducción. Corresponsales y colaboradores de la revista La Rábida", en Huelva y América. Cien años de Americanismo: Revista "La Rábida” (1911-1933). De corresponsales y colaboradores. (Coord. R. Márquez Macías). Sevilla: Universidad Internacional de Andalucía, 9-14.

CANO BALLESTA, J. (1972). La poesía española entre pureza y revolución. Madrid: Gredos.

CHICHARRO CHAMORRO, A. (2004). Para una historia del pensamiento literario en España. Madrid: CSIC.

[DÍAZ-PLAJA, G.] “SAGITARIO” (1943). "La saeta en el aire”. Destino 301: 10.

ECHEVARRÍA, I. (2002). "Entrevista: Antonio Ferres y Juan Eduardo Zúniga. Una generación olvidada. 'Todos somos seres perdidos"'. El País (02/11/2002). <http://elpais.com/diario/2002/11/02/babelia/1036197551_850215.html> (Acceso 6 Mayo 2015).

ESPAGNE, M. (2009). "Transferts culturels et histoire du livre". Histoire et civilisation du livre 5: 201-213.

GARCÍA URETA, Í. (2011). Éxito. Un libro sobre el rechazo editorial. Madrid: Trama.

GRÀCIA GARCIA, J. y RUIZ CARNICER, M. A. (2001). La España de Franco (1939-1975). Cultura y vida cotidiana. Madrid: Síntesis.

MADRIGAL NEIRA, M. (2004). La memoria no es nostalgia: José Caballero. Memoria para optar al grado de Doctor, dirigida por Lucís García de Capri. Madrid: Universidad Complutense de Madrid.

MARTÍNEZ CACHERO, J. M. (1997). La novela española entre 1936 y el fin de siglo: historia de una aventura. Madrid: Castalia. 
MARTÍNEZ RUIZ, J. “AZORÍN” (1917). "La crítica”. Páginas escogidas. Madrid: Calleja.

MOLINA, C. A. (1990). Medio siglo de prensa literaria española (1900-1950). Madrid: Endymión.

[PLA, J.] TRISTÁN (1947). “Jean-Paul Sastre y el 'tremendismo' literario". Destino 501: 6-7.

PULIDO HIDALGO, M. (2009). Plutarco de moda: la biografía moderna en España, 1900-1950. Mérida: Editora Regional de Extremadura-Universidad de Extremadura.

RIPOLL SINTES, B. (2011). "La influencia de la literatura extranjera en la novela española de posguerra. Una cuestión de modernidad", en Del verbo al espejo. Barcelona: PPU: 169-176.

RIPOLL SINTES, B. (2012). “Destino” y la novela española de posguerra (19391949). Vigo: Editorial Academia del Hispanismo.

RIPOLL SINTES, B. (2013). "Las traducciones en la posguerra española: Rafael Vázquez-Zamora". La main de Thôt 1 (Genre et traduction, mis en ligne le 04/11/2013). <http://e-revues.pum.univ-tlse2.fr/sdx2/la-main-de-thot/article. xsp?numero=1\&id_article=Portrait_par_Blanca_Ripoll-723>. (Acceso 6 Mayo 2015).

RIPOLL SINTES, B. (e.p.). "La fiesta de la novela: el Premio Nadal y su función como antecedente del sistema español de certámenes literarios". Barcelona: ciudad de novela. Barcelona: Publicacions de la Universitat de Barcelona.

RODRÍGUEZ ESPINOSA, M. (2004). "El discurso ideológico de la censura franquista y la traducción de textos literarios: Las aventuras de Barry Lyndon y la Editorial Destino", en Ética y política de la traducción literaria. (Ed. Grupo de Investigación Traducción, Literatura y Sociedad). Málaga: Universidad de Málaga: 219-238.

ROJAS, P. (2008). "Algunas notas sobre la revista Rumbos (1935-1936) y su nómina de colaboradores". Docencia e Investigación: revista de la Escuela Universitaria de Magisterio de Toledo 18: 1-20.

RUIZ SORIANO, F. (1997). La poesía de postguerra: vertientes poéticas de la primera promoción. Barcelona: Literatura y Ciencia.

SANTOS, D. (1987). De la turba gentil... y de los nombres. Barcelona: Planeta.

SANZ ROIG, D. (2013). "Los proyectos editoriales de Mario Verdaguer: La revista Mundo Ibérico y las editoriales Lux y Apolo". Revista de Literatura, vol. 75, 149 (enero-junio): 179-205.

SOBEJANO, G. (1962). "La situación actual de la crítica literaria en España", en Vereniging van Leraren en Levende Talen. Berichten en mededeelingen van 
de Vereeniging van Leeraren in Levende Talen Berichten, J. B. Wolters 213 (febrero), pp. 74-90. http://www.cervantesvirtual.com/FichaObra.html?portal= 301\&Ref=32156. (Acceso 6 Mayo 2015).

UNAMUNO, M. de (2007). Ensayos, Obras Completas. Vol. VIII (ed. Ricardo Senabre). Madrid: Biblioteca Castro - Fundación José Antonio de Castro.

VERDUGO ÁLVEZ, N. (2014). "Colaboradores onubenses de la revista La Rábida", en Huelva y América. Cien años de Americanismo: Revista "La Rábida” (1911-1933). De corresponsales y colaboradores. (Coord. R. Márquez Macías). Sevilla: Universidad Internacional de Andalucía: 15-53.

VÁZQUEZ ZAMORA, R. (1934). "Prólogo" a Vida de Jesucristo, Carlos Dickens. Barcelona: Apolo.

VÁZQUEZ ZAMORA, R. (1935). "Cubilete de dados". El Heraldo de Madrid (28/03/1935): 4.

VÁZQUEZ ZAMORA, R. (1943). “CAMILO JOSÉ CELA: La familia de Pascual Duarte". Destino 296: 10.

VÁZQUEZ ZAMORA, R. (1944a). “Cinco minutos con Azorín”. Destino 350: 10. VÁZQUEZ ZAMORA, R. (1944b). "El despiadado don Pío”. Destino 371: 7. VÁZQUEZ ZAMORA, R. (1944c). "Puntos de vista”. Destino 386: 13.

VÁZQUEZ ZAMORA, R. (1945a). “¿Conoce usted la vida?”. Destino 395: 13.

VÁZQUEZ ZAMORA, R. (1945b). "Carta sin sobre a María Fontán”. Destino 400: 21-22.

VÁZQUEZ ZAMORA, R. (1945c). “Azorín, ermitaño en el bullicio”. Destino 405: 19.

VÁZQUEZ ZAMORA, R. (1946). “Alrededor de una colmena”. Destino 445: 13. VÁZQUEZ ZAMORA, R. (1947). “Un día cualquiera de Azorín”. Destino 528: 10.

VÁZQUEZ ZAMORA, R. (1948a). "La vida de los libros". Destino 549: 14. VÁZQUEZ ZAMORA, R. (1948b). "La vida de los libros”. Destino 569: 16. VÁZQUEZ ZAMORA, R. (1949). "La vida de los libros”. Destino 621: 15-16. VÁZQUEZ ZAMORA, R. (1950). "La vida de los libros". Destino 691: 15. VÁZQUEZ ZAMORA, R. (1951). "La vida de los libros". Destino 733: 15-16. VÁZQUEZ ZAMORA, R. (1954). "La vida de los libros". Destino 903: 32-33 VÁZQUEZ ZAMORA, R. (1957). "La vida de los libros", Destino 1021: 32 WILDE, O. (1985). The Picture of Dorian Grey. London: Penguin Book. 